
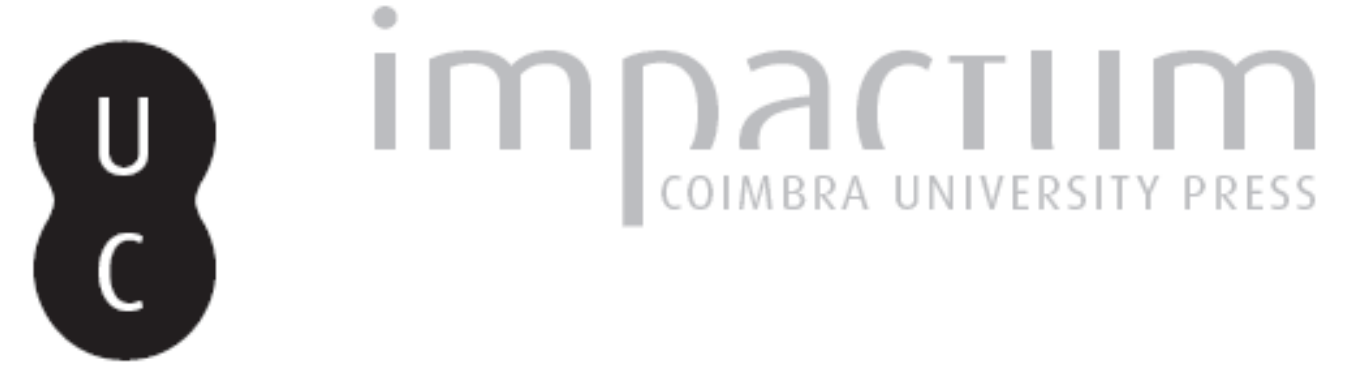

\title{
Ideias da arquitectura portuguesa em viagem
}

Autor(es): $\quad$ Emília, Cristina; Furtado, Gonçalo

Publicado por: Editorial do Departamento de Arquitetura

URL persistente:

URI:http://hdl.handle.net/10316.2/38795

DOI:

DOI:http://dx.doi.org/10.14195/1647-8681_3_16

Accessed : $\quad$ 26-Apr-2023 14:56:21

A navegação consulta e descarregamento dos títulos inseridos nas Bibliotecas Digitais UC Digitalis, UC Pombalina e UC Impactum, pressupõem a aceitação plena e sem reservas dos Termos e Condições de Uso destas Bibliotecas Digitais, disponíveis em https://digitalis.uc.pt/pt-pt/termos.

Conforme exposto nos referidos Termos e Condições de Uso, o descarregamento de títulos de acesso restrito requer uma licença válida de autorização devendo o utilizador aceder ao(s) documento(s) a partir de um endereço de IP da instituição detentora da supramencionada licença.

Ao utilizador é apenas permitido o descarregamento para uso pessoal, pelo que o emprego do(s) título(s) descarregado(s) para outro fim, designadamente comercial, carece de autorização do respetivo autor ou editor da obra.

Na medida em que todas as obras da UC Digitalis se encontram protegidas pelo Código do Direito de Autor e Direitos Conexos e demais legislação aplicável, toda a cópia, parcial ou total, deste documento, nos casos em que é legalmente admitida, deverá conter ou fazer-se acompanhar por este aviso.

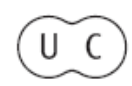




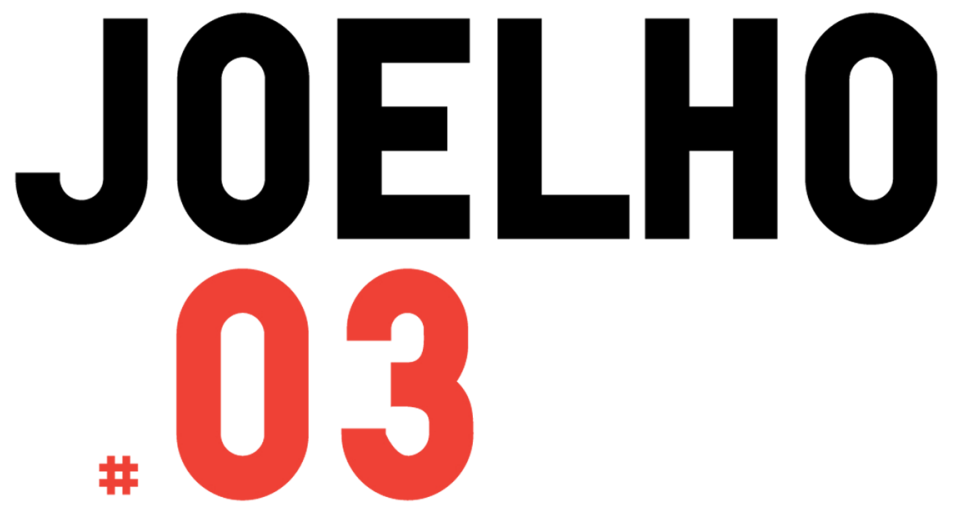

VIAGEM-MEMÓRIAS: APRENDIZAGENS DE ARQUITECTURA

Coordenação:

Alexandre Alves Costa

Domingos Tavares

Exposição Viagem

Exposição Memórias

Luis Mansilla

Alexandre Alves Costa Domingos Tavares

Scafol DiNG
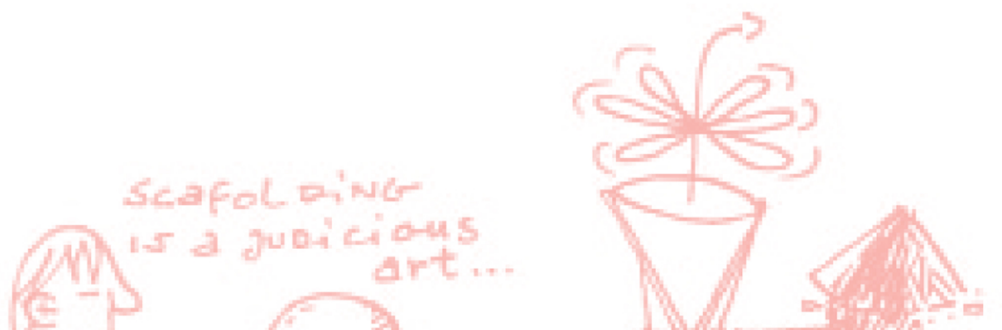

Jorge Figueira José Miguel Rodrigues José António Bandeirinha José Fernando Gonçalves Paulo Providência Gonçalo Canto Moniz Armando Rabaça Patrícia Miguel Bruno Gil
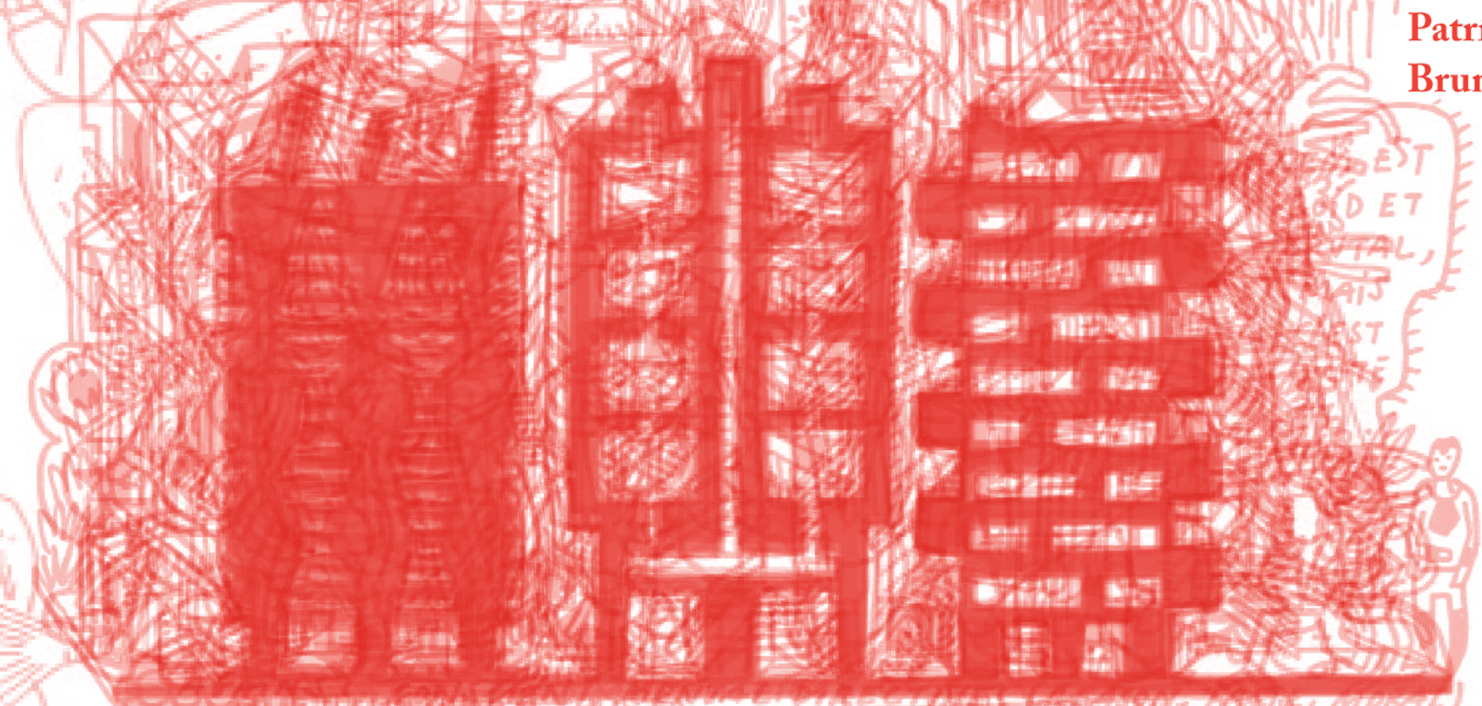

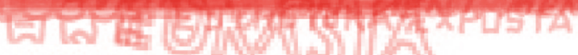
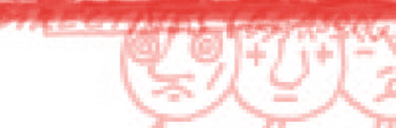


\section{Cristina Emília e Gonçalo Furtado Ideias da Arquitectura Portuguesa em viagem}

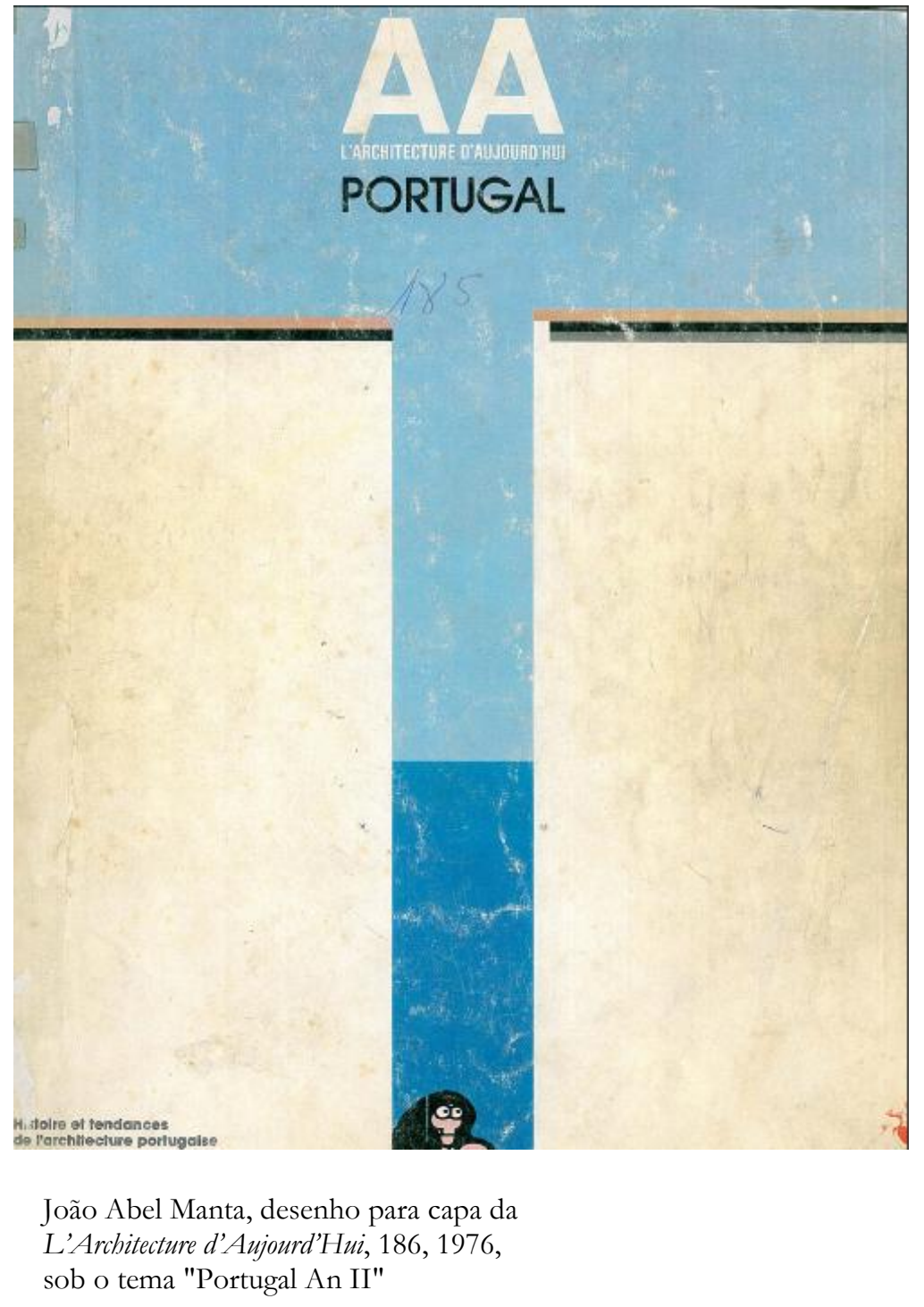




\section{Resumo}

Consideramos que um contacto directo e sensorial com as obras de arquitectura é insubstituível: o percepcionar o território que as envolve, assim como a experiência corpórea da espacialidade interior aporta, através dos nossos sentidos, uma quantidade inestimável de informação. Porém, não se pode negar que a leitura de textos e a observação de imagens particulares nos fazem viajar em territórios que nunca habitámos, mas que se registam indelevelmente nas nossas memórias. Outras vezes, viajamos não com o objectivo de destinos geográficos, mas sim, para irmos ao encontro de pessoas que nos abrem as portas de outros locais que até ali não soubéramos percorrer. Habituados que muitos estão a considerar o nosso País como lugar onde as 'novidades' chegam frequentemente com anos de desfasamento, e a serem forçados a viajar para fora das suas fronteiras para contactar com tais novidades prontamente, é no entanto relevante perceber que a Arquitectura Portuguesa teve e tem o poder de despertar as atenções de arquitectos e críticos internacionais, e ser apontada como pioneira e exemplar ao nível internacional. Já em plena década de 70, quando os media e a facilidade em viajar não era tão grande como a actual, constata-se que a Arquitectura Portuguesa passou a marcar de forma consistente as publicações internacionais da especialidade. Curiosamente este processo teve por base viagens físicas empreendidas por pessoas. No presente artigo, propomo-nos delinear alguns itinerários que a Arquitectura Portuguesa percorreu fora do território nacional e identificar os protagonistas com quem viajou rumo ao reconhecimento internacional que detém actualmente. Referência será feita a casos como Eduardo Anahory e a publicação $W$ orld Architecture em Inglaterra, entre outros da década de 50 e 60. Expor-se-á como as viagens do arquitecto Nuno Portas e o interesse de arquitectos e editores do Sul da Europa, como por exemplo Oriol Bohigas, Vittorio Gregotti, Bruno Alfieri ou Bernard Huet, oriundos de Espanha, Itália e França, ou os encontros em seminários com a presença de nomes como Aldo Rossi, entre outros, fizeram do ano de 1976 um ano de autêntica viragem, de colocação da Arquitectura Portuguesa sob os holofotes da cena internacional arquitectónica. Em grande medida, os arquitectos Portugueses mostraram e ensinaram então, aos seus congéneres internacionais, hipóteses de saídas para a chamada Crise do Movimento Moderno. E, seriam necessários poucos anos, para que passássemos de uma situação de ser forçados a sair, para atrairmos outros a viajarem ao interior do nosso País e Arquitectura.

\section{Alguns percursos da década de 50 a $70^{1}$}

Relativamente à década de 50 gostávamos de destacar uma exposição organizada pelo Sindicato Nacional dos Arquitectos em conjunto com o Secretariado Nacional de Informação, intitulada "Contemporary Portuguese Architecture". Esta fez itinerância por várias cidades Inglesas, nomeadamente Londres, onde esteve patente no Building Centre, em 1956, tendo também sido exibida nos EUA, onde temos notícia de ter estado em Washington, no Smithsonian Institution, em 1958. A selecção efectuada incluía obras dos arquitectos: Viana de Lima, Fernando Távora, Formosinho Sanches, Agostinho Ricca, Arménio Losa, Cassiano Barbosa, 
Ruy d'Athouguia, Teotónio Pereira, Bartolomeu Cabral, Alberto Pessoa, Hernani Gandra, Abel Manta, Manuel Laginha, João Esteves, Pedro Cid, ARS arquitectos, Januário Godinho, Keil Amaral, José Loureiro, Manuel Tainha, António Freitas, Raul Ramalho e Maurício de Vasconcelos 2 .

Um dos percursos que apontamos como pioneiro é o do Português Eduardo Anahory marcado por inúmeras viagens e contactos internacionais. As viagens e estadias que Anahory realizou no estrangeiro ao longo da sua vida, resultariam numa extensão do seu círculo de relações profissionais e pessoais, assim como influenciaram o seu trabalho. Anahory trabalhou como pintor, ilustrador, cenógrafo, figurinista, e apesar de não ter chegado a concluir o curso de Arquitectura, como arquitecto ${ }^{3}$. Com apenas 22 anos viajou para Nova Iorque com vista a trabalhar no pavilhão Português da World's Fair de 1939 (Borges, 2010, p.31). Viveu várias temporadas no Brasil ${ }^{4}$, onde colaborou com os arquitectos Oscar Niemeyer e Eduardo Reidy, entre outros, coincidindo com uma época em que a arquitectura moderna Brasileira estava em elevado desenvolvimento e usufruía de reconhecimento internacional ${ }^{5}$. Viveu em Paris, entre 1945-48, (Borges, 2010, p.41), realizou uma viagem de estudo trimestral à Suécia, Noruega, Dinamarca e Finlândia, em 1963, onde procurou trabalhar com Alvar Aalto (Borges, 2010, p.124). Foi correspondente da revista Francesa L'Architecture d'Aujourd'Hui entre 1959 e 1963 e é conhecida a sua amizade com Gio Ponti, fundador e director da revista Italiana Domus, (Borges, 2010, p.58).

Seria no entanto, aquando da sua estada em Portugal entre 1955 e 1974, que Anahory realizou obras arquitectónicas que granjearam um reconhecimento internacional, plasmado na sua publicação em revistas internacionais. De facto, as suas obras são frequentemente publicadas ${ }^{6}$ desde finais da década de 50 até meados da de 60. Nomeadamente, mediante publicação em praticamente um número por ano na revista L'Architecture d'Aujourd'Hui, no período compreendido entre 1958-65; com excepção dos anos 1960 e 1964 em que o seu trabalho não foi publicado em nenhuma edição, tendo no entanto, sido editado duas vezes em 1962 e 63. Na revista Domus teve presença num número por ano entre 1960 e 66, com excepção do ano de 1965. No ano de 1962, foi ainda publicado na revista Alemã Moebel Interior Design. Esta publicação veio no seguimento da sua presença na revista Domus, através da qual Oriol Bohigas tomou conhecimento da sua obra (Correia, 2010, p24). Bohigas era à época correspondente da revista referida em Espanha, e aproveitou ter conhecido o arquitecto Português José Aleixo de França Sommer Ribeiro numa recepção no RIBA de Londres para estabelecer contacto com Anahory (Correia, 2010, p24). No ano seguinte, em 1963, os seus trabalhos foram, como referido, editados em Itália na revista Domus, em França na L'Architecture d'Aujourd'Hui, também na Alemanha, numa revista de nome DBZ - Deutsche Bauzeitschrift, e ainda em Inglaterra, na Architectural Review, na Suíça, na Bauen+Wobnen e no Brasil na Arquitectura. Em 1965, como referimos, o seu trabalho mereceu a atenção em França da L'Architecture d'Aujourd'Hui, onde também teve o seu trabalho publicado na UIA (Revue de L'Union Internationale des Architectes), e apesar de neste ano não ter sido publicado na Domus, foi-o na Italiana Lotus International, repetindo-se a 
sua edição na Alemanha, na revista $D B Z$ e na Suíça, na Bauen+Wobnen. Para além das revistas referidas, a casa Aiola terá sido publicada na revista Alemã Neue Wobnhauser, na Francesa Connaissance des Arts, na Suíça 33 ArchitektenEinnfamilienhauser, e incluso chegou aos EUA através da House Beautiful, e no livro Vacation Houses: an International Survey de Karl Kasper (Nova Iorque, Praeger) de 1967.

Para além de Anahory pode fazer-se referência a outros autores. Em particular Ruy d'Athouguia, tendo sido publicado internacionalmente na revista Suíça Bauen+Wobnen, na Alemã Innendkoration / Architektur Und Wohnform, na Francesa L'Architecture d'Aujourd'Hui (Correia, 2008, p.14), e no livro Suíço Das Haus des Architekten, de Robert Winkler ${ }^{7}$, na década de 50. O seu edifício do Bairro das Estacas, projectado em co-autoria com Formosinho Sanchez, ganhou mesmo um prémio na Segunda Bienal de Arquitectura de São Paulo (1954?) (Correia, 2008, p.104).

Referência foi já feita a outros autores como Fernando Távora, o qual teve a sua Escola Primária do Cedro publicada na L'Architecture d'Aujourd'Hui, em 1965. No ano seguinte, outro arquitecto Português, Nuno Teotónio Pereira, igualmente já referido, viu também publicada a sua Moradia em Sesimbra na Schöner Wohnen, e em 1972, o edifício Franjinhas no livro $A$ arquitectura Moderna ${ }^{8}$ do Italiano Gillo Dorfles. Este livro também inclui uma imagem da Fundação Calouste Gulbenkian, dos arquitectos Portugueses Alberto Pessoa, Ruy d'Athouguia e Pedro Cid', a qual foi fundamental no panorama cultural arquitectónico em Portugal, tendo também tido eco em França, na revista L'Oeil em 1970, e em Inglaterra, numa Architectural Design de 1973 (Tostões, 2006, p.216).

Atenda-se que neste momento, a publicação de autores Portugueses será seguida pela publicação já centrada na temática mais geral da Arquitectura Portuguesa. Neste sentido refira-se que Luiz Sarmento Carvalho e Cunha (1933) foi contactado pela equipa editorial do livro World Architecture dirigida por John Donat, para publicar um artigo sobre arquitectura Portuguesa ${ }^{10}$. John Donat terá tido conhecimento de Távora e de Siza Vieira, pelo arquitecto Português Pancho Guedes, que visitara algumas das suas obras em 1960, aquando duma viagem à Europa (Milheiro, 2007, p.6,8). O World Architecture One, o primeiro livro da série foi editado em 1964, em Inglaterra. Refira-se que a série $W$ orld Architecture tinha por objectivo fomentar uma crítica da arquitectura internacional (Donat, 1964, p.8), tendo saído mais três volumes, nos quais se constata que Portugal já não seria referenciado ${ }^{11}$, ainda que tenha sido mantido o capítulo referente a Moçambique, com obras do Português Pancho Guedes. No primeiro volume desta série, o referido Luiz Cunha escreveu sobre a arquitectura do Norte de Portugal, nomeadamente centrando-se em Januário Godinho, Viana de Lima, Fernando Távora e Álvaro Siza Vieira, tendo estes dois últimos arquitectos incluído textos de sua autoria. De acordo com Cunha, esta pode ter sido a primeira publicação internacional da obra do arquitecto Português Siza Vieira $^{12}$, que como se sabe, teve um papel fundamental na visibilidade da Arquitectura Portuguesa.

Relativamente a Luiz Cunha, refira-se que este tinha já realizado ilustrações para o livro que Robert Auzelle publicara em França em 1962 ${ }^{13}$, no seguimento da sua convivência na Câmara Municipal do Porto ${ }^{14}$. (No 
mesmo ano, estas ilustrações forma referenciadas na L'Architecture d'Aujourd'Hui' ${ }^{15}$.) Tal colaboração, entre Cunha e Auzelle, repetiu-se em artigos publicados na revista francesa Urbanisme ${ }^{16}$. Quatro anos mais tarde, Luiz Cunha veria ainda ser publicadas duas igrejas de sua autoria na revista Italiana Rocca ${ }^{17}$.

A meio da década de 60 , como já referido, para além da publicação internacional de arquitectos Portugueses, a Arquitectura Portuguesa em si, surge já como um tema. Especial destaque neste processo deve ser feito para Nuno Portas que teve um papel seminal na divulgação e reconhecimento da Arquitectura Portuguesa Contemporânea ao nível internacional. Portas realizou inúmeras viagens enquanto director da revista Arquitectura $^{18}$, como quadro do Laboratório Nacional de Engenharia Civil $^{19}$, ou motivadas pelos seus interesses pessoais, que se estendiam até ao cinema. Foi este interesse de Portas que o influenciou a usar a estratégia que o governo Francês seguia na época para a divulgação do 'cinema de autor' 'La politique des auteurs ${ }^{20}$. Por isto, Portas entende consistir em divulgar um tema principal e outro secundário, bem como destacar um autor de entre um conjunto de outros dois ou três de segundo plano ${ }^{21}$. Portas avançou com a divulgação dos temas da arquitectura de autor e dos estudos e obras sob o programa da habitação social, e do autor Álvaro Siza Vieira, em simultâneo com Fernando Távora e Teotónio Pereira ${ }^{22}$. Nas frequentes viagens que fez cultivou contactos, pois como afirma "são coisas que levam tempo" ${ }^{23}$, os quais demonstrariam terem sido prolíferos. De entre eles, destaca-se por exemplo, um encontro num café de Milão que teve com o Italiano Vittorio Gregotti e o Norte-Americano Robert Venturi, que possibilitou 'trocar' livros acabados de editar pelos três autores: Arquitectura para hoje (1964), O território da arquitectura (1966) e Complexidade e Contradição na Arquitectura (1966) ${ }^{24}$. Estes contactos foram reforçados por outras pessoas, nomeadamente por Duarte Cabral de Mello ${ }^{25}$, que nas suas frequentes visitas a Espanha na década de 60, contactava com arquitectos e editores, motivado por Portas e pela actividade de editor que este desenvolvia na revista Arquitectura. Outro ponto de encontro de experiências e pessoas foram os Pequenos Congressos Espanhóis, da iniciativa dos arquitectos Oriol Bohigas e Carlos de Miguel (Correia, 2010). Em 1967, Portas e Anahory participariam no $8^{\circ}$ Pequeno Congresso em Tarragona, o que teve como consequência a realização em Portugal ainda em Dezembro do mesmo ano, de um Congresso similar em Tomar ${ }^{26}$. O programa deste evento incluía uma visita a Lisboa (para conhecer os Olivais), e ao Norte (a obras de Siza Veira). Uma consequência deste Pequeno Congresso foi o artigo de Bohigas publicado na revista Espanhola Serra d'Or, no ano seguinte, sob o título "A Portugal també els arquitectes fan la guerra pel seu compte" (Correia, 2010, p.27). Os arquitectos Portugueses continuariam a marcar presença nos Pequenos Congressos em Vitória em 1968, e em La Garriga, em 1970. Em Vitória, estariam presentes para além de Portas, que fez uma apresentação de Siza Vieira, o próprio Siza, que expôs o seu trabalho, Fernando Távora ${ }^{27}$ e Duarte Cabral de Mello $^{28}$. Terá sido aqui que o Italiano Vittorio Gregotti tomou contacto directo com Siza Vieira ${ }^{29}$. Ressalte-se que neste colóquio estiveram presentes protagonistas internacionais como Peter Eisenman, e falava-se 
uma diversidade de línguas que iam de Basco, Catalão, Espanhol, Português, Italiano, Francês ao Inglês ${ }^{30}$. Em La Garriga estiveram presentes para além de Portas, Távora, Siza Vieira e Duarte Cabral de Mello, Manuel Tainha (Correia, 2010, p.30).

No ano de 1969, Portas integrou uma visita de estudo aos EUA, num grupo composto por Oriol Bohigas, Rafael Moneo, Fernandez Alba, Frederico Correa, onde contactaram directamente com Peter Eisemman e Kenneth Frampton. Interessa ressaltar o encontro de Frampton com os arquitectos Portugueses, que seria igualmente prolífero, tal como a colaboração de Duarte Cabral de Mello no Institute for Architecture and Urban Studies (IAUS), em Nova Iorque, convidado por Eisenman, seu director, no referido Congresso de Vitória ${ }^{31}$. Mello trabalhou naquele Instituto, com uma bolsa americana, desde Setembro de 1970 até ao final de 1972, onde contactou para além de Eisenman e Frampton, com Mário Gandelsonas, Adriana Agreste, Joseph Ryckwert, Anthony Vidler, Colin Rowe, Michael Graves e Susana Torre, entre outros ${ }^{32}$. Durante a sua estadia, Eisenman propôs a Mello publicar o trabalho de Siza Vieira na revista Oppositions, editada pelo Instituto, mas por falta de disponibilidade de Siza, tal não chegou a concretizar-se. Após a referida viagem aos EUA, Portas redireccionou os seus interesses e destinos da América do Norte para a América do Sul ${ }^{33}$.

Anos mais tarde, a 'revolução dos cravos' de 1974 em Portugal, constituiria um acontecimento que exponenciou o interesse internacional sobre o País e como corolário, pela sua arquitectura. No seu seguimento, Portas assumiu as funções de Secretário de Estado da Habitação e Urbanismo em 1974 e 1975, implementando as conhecidas operações $\mathrm{SAAL}^{34}$, continuando ainda no motor do desenvolvimento da arquitectura Portuguesa e sua divulgação. Outras viagens memoráveis foram as que Portas realizou a Itália em 1974 e 1975, para fazer conferências sob o tema das operações SAAL. Na primeira viagem, fez uma conferência na conceituada escola de Veneza; e na segunda, realizou um périplo por dez escolas italianas acompanhado por Alexandre Alves Costa e Siza Vieira ${ }^{35}$.

Neste contexto, Portas publicaria vários artigos sobre a Arquitectura Portuguesa e a obra de Siza Vieira em revistas internacionais, as quais começam a dedicar-lhes maior atenção. A primeira consequência concreta destas interacções está plasmada numa revista Espanhola Hogary Arquitectura, de 1967 editada por Carlos Flores, que é quase inteiramente dedicada ao trabalho de Siza Vieira, com artigos da autoria de Nuno Portas e Pedro Vieira de Almeida. Como refere Flores no seu editorial, existia um desconhecimento por parte dos arquitectos Espanhóis sobre a arquitectura Portuguesa. Façamos um parêntesis, para referir que Portas se lembra do impacto que o Inquérito à Arquitectura Popular em Portugal teve em Flores quando lhe mostrou, pois em Espanha, tal ainda só estava iniciado ${ }^{36}$. Neste sentido, Flores deslocou-se a Portugal para falar com Keil do Amaral, inquérito que acabou por realizar sozinho em Espanha ${ }^{37}$.

Se a arquitectura Portuguesa começara a ser conhecida em Espanha, há registos de na mesma revista Hogary Arquitectura, no anterior ano de 1966, terem sido publicados trabalhos da autoria de arquitectos Portugueses: as "Viviendas conómicas en Olivais-Sul. Lisboa" de Bartolomeu Costa 
Cabral, e o artigo intitulado "Urban equipment en Portugal" de Francisco Pires Keil do Amaral e José de Santa Bárbara. Os dois últimos autores, em 1971, publicaram na mesma novo artigo intitulado "Portugal: Raices de un Townscape". Keil, que havia conhecido Carlos Flores numa viagem de férias que fez a Madrid, explica que estas foram as únicas publicações internacionais ${ }^{38}$.

Como já referido, os anos 60/70 são marcados por Portas que será decisivo na visibilidade da arquitectura Portuguesa. No seguimento, em 1970, é publicado na revista Argentina Cuadernos Summa Nueva Visión um artigo de sua autoria, intitulado "Arquitecturas Marginadas en Portugal" 39 . Em 1972, na revista Italiana Controspazio, publicou outro artigo intitulado "Note sul significato dell'architettura di Álvaro Siza nell'ambiente portoghese" na qual Gregotti fez uma apresentação do trabalho desse arquitecto, o que constitui a primeira abordagem por um autor internacional ao trabalho do Português. (No ano anterior, em 1969, tinha já sido editado na Suíça, a Casa de Chá de Siza Vieira na revista Architecture, Formes et Fonctions, restringindo-se à publicação dos elementos de projecto: material gráfico e memória descritiva.) Também em Espanha, em 1975, Portas colaborou com a edição do Diccionario Ilustrado de la Arquitectura Contemporânea (Hatje, 1975) com artigos sobre "Portugal" e "Siza Vieira". Obras de Siza e as operações SAAL, sob o título "Il Portogallo dopo il 25 Aprile", (Setúbal, Forte Velho e o plano de Urbanização da Moita), são incluídas na revista Italiana Lotus International, no segundo e terceiro volume, dos três dedicados ao tema 'Casa', editados por Bruno Alfieri, em 1974 e 1975.

\section{O seminal ano de 1976}

No seguimento do contexto referido, o interesse consistente de autores internacionais na arquitectura Portuguesa, expresso mediante artigos específicos e concessão de espaço nas publicações / exposições, aconteceu no ano de 1976. Neste ano surgiram edições em vários Países dedicados a Portugal, nomeadamente em Espanha, Itália ou França.

Relativamente a Espanha foram publicadas na revista Arquitectura Bis artigos sobre o trabalho de Siza Vieira da autoria de Rafel Moneo e Bohigas. O texto deste último autor seria reeditado no mesmo ano no livro Once Arquitectos (Bohigas, 1976) e na revista Francesa L'Architecture d'Aujourd'Hui.

Relativamente a Itália, Bruno Alfieri, publicou na Lotus International e na Casabella, enquanto director de ambas, o trabalho do arquitecto Siza Vieira num número da primeira, e as operações SAAL em números das duas revistas.

Relativamente a França, Bernard Huet, editor da revista L'Architecture d'Aujourd'Hui, publicou um dossier intitulado "Portugal An II", que contou com a colaboração em termos de coordenação de Raul Hestnes Ferreira e seu colaborador Manuel Miranda. Vários seriam os artigos escritos por autores Portugueses incluídos, os quais se detiveram sobretudo sobre a história recente da arquitectura Portuguesa (entre 1930 e 1974), ainda que Gonçalo Byrne e Hestnes Ferreira ${ }^{40}$ tenham tratado a sua contemporaneidade. Os autores estrangeiros reflectiram, por seu lado, sobre 
o trabalho de Siza Vieira (Huet, Gregotti ${ }^{41}$, e Bohigas); e as operações SAAL, (por Brigitte David).

Também em 1976, realizou-se uma exposição sobre o arquitecto Siza Vieira, que merece ser referida por ter tido lugar na Dinamarca, Aarhus.

De entre outros eventos, merecem destaque o I Seminário Internacional de Arquitectura em Compostela (ISIAC, Santiago de Compostela) e a Bienal em Veneza sob o tema Europa - América. O ISIAC em 1976 teve como director Aldo Rossi, e contou com uma elevada presença de arquitectos internacionais como Mário Gandelsonas ou James Stirling ${ }^{42}$, e Portugueses, nomeadamente Siza Vieira e Charters Monteiro. Foi neste encontro que Aldo Rossi conheceu Siza Vieira, por intermédio de Charters que contactava com ele desde 1969, aquando da realização da sua tese final de curso $^{43}$. Como sabido, Charters Monteiro estudou em Itália entre 1963 / 69, onde estabeleceu uma relação com Rossi que incluiu, por exemplo a tradução Portuguesa do seu livro A Arquitectura da Cidade, mantendo-se vivo o seu interesse por Portugal, o qual visitou várias vezes, nomeadamente no $1^{\circ}$ de Maio de $1974^{44}$. Siza Vieira esteve para ser publicado na revista L'architettura. Cronache e storia do Italiano Bruno Zevi, tendo Charters recolhido elementos junto do arquitectos Português nas férias de Verão de 1964, a pedido de Portas, que por sua vez tinha sido contactado por Zevi. No entanto, e na sequência de posições reaccionárias que Zevi tomou perante os estudantes de arquitectura, Charters recusou-se a concluir o trabalho, ficando a publicação sem efeito ${ }^{45}$. Siza Vieira também esteve presente na Bienal de Veneza de 1976, a qual punha em contraponto o trabalho de arquitectos Europeus com o de arquitectos Americanos. Esta Bienal fomentou o encontro e troca de ideias, nomeadamente através de um debate entre pessoas como Aymonino, De Carlo, Hertzberger, Bohigas, Rossi, Smithsons, Stirling, Ungers, Van Eyck, Eisenman, John Hejduk, Stern, Venturi, Brown ${ }^{46}$.

No primeiro capítulo falámos de alguns percursos da década de 50 a 70 que levaram ao seminal ano de 1976. Como referido na introdução o contacto com as obras é insubstituível, mas são relevantes aquelas viagens que as palavras e imagens de arquitectura publicadas em revistas, livros e catálogos nos permitem fazer, assim como as viagens físicas que os autores fazem para conhecer outros. Ficou clara a importância das viagens e dos encontros na divulgação da Arquitectura Portuguesa. No caso Português, de entre estes percursos destacámos Anahory, Athouguia, Távora, Teotónio Pereira, Mello e Charters Monteiro, e as revistas Domus, Lotus International, Controspazio L'Architecture d'Aujourd'Hui, Moebel Interior Design, Bauen+Wobnen, $D B Z$, entre outras. Com o avançar da década de 60 , a publicação de autores Portugueses leva à emergência do tema da Arquitectura Portuguesa por si. Nesta passagem é relevante a política de autores empreendida por Portas, divulgando o trabalho de Siza Vieira e a habitação social. Foi reconhecido internacionalmente o mérito e o empenho por parte dos arquitectos Portugueses em resolver as preocupações com a habitação social, que se estendiam um pouco por toda a Europa; bem como em procurar respostas mais satisfatórias e inovadoras perante os problemas que se punham, corporizadas no trabalho de Siza Vieira. O tema da Arquitectura Portuguesa, consolidou-se com autores Portugueses, para além de Portas, 
com Luiz Cunha, Hestnes Ferreira, José Augusto França, entre outros aqui referidos, assim como a sedução que por ela sentiram autores e editores internacionais como Donat, Flores, Gregotti, Alfieri, Bohigas, Huet, David, Rossi. E se as viagens e encontros que aqui se relataram produziram resultados concretos com publicações que perduram no tempo como testemunhos, provavelmente outros tantos haveria para contar, que a terem sido consequentes poderiam ter escrito outras páginas sobre a percepção internacional da Arquitectura Portuguesa.

\section{Bibliografia}

Bohigas, O. (1976), Once

Arquitectos, Barcelona: La Gaya Ciencia.

Borges, J. A. B., (2010), Eduardo Anahory, percurso de um designer de arquitectura, dissertação para a obtenção do grau de mestre em Arquitectura, Lisboa: Instituto Superior Técnico, Universidade Técnica de Lisboa.

Correia, G, (2008), Ruy Jervis d'Athonguia - A Modernidade em Aberto, Lisboa: Caleidoscópio.

Correia, N. (2009/2010), O Nome dos Pequenos Congressos. A primeira geração de encontros em Espanba 1959-1967 e o pequeno congresso de Portugal, Barcelona: Universidade Politécnica da Catalunha, ETSAB.

Donat, J. (Coord.) (1964), World Architecture One, Londres: Studio Books London.

Milheiro, A., "No fim do Mundo", In Guedes, P., (2007), Manifestos, Ensaios, Falas, Publicações, (pp 6 - 9), Lisboa: Ordem dos Arquitectos.

Hatje, G., (1975), Diccionario Ilustrado de la Arquitectura Contemporânea, Barcelona: Gustavo Gili.

Tostões, A., (2006), Fundação Calouste Gulbenkian. Os edifícios, Lisboa: Fundação Calouste Gulbenkian, Edifícios Centrais. 


\section{Revistas internacionais}

Architecture, Formes et

Fonctions, 1969

Casabella, 1976

Controspazio, 1972

Cuadernos Summa Nueva

Visión, 1970

Lotus International, anos 60 a 70

\author{
Domus, anos 60 \\ Hogar y Arquitectura, 1955 -
} 77

L'Architecture

d'Aujourd'Hui, anos 50 a 70

${ }^{1}$ Para a realização deste trabalho, Cristina Emília Silva foi apoiada com bolsa de Doutoramento da FCT. Gonçalo Furtado é docente no Programa de Doutoramento em Arquitectura na FAUP.

${ }^{2}$ Arquivo de António Neves.

${ }^{3} \mathrm{O}$ percurso de Anahory é descrito por Borges, J. A. B., (2010), em Eduardo Anahory, percurso de um designer de arquitectura, dissertação para a obtenção do grau de mestre em Arquitectura, Instituto Superior Técnico, Universidade Técnica de Lisboa.

${ }^{4}$ Entre 1940-45 (Borges, 2010, p37), 1952-55 (ibidem, p.49), e 1974-83, (ibidem, p166). Na década de 70 a sua actividade profissional repartia-se por Angola e Brasil, (ibidem, p 162).

Regressou a Portugal em 1983 onde morreu em 1985, (ibidem, p168).

${ }^{5}$ Em 1943 ocorreu a exposição em Nova Iorque que viria a originar o sobejamente conhecido catálogo "Brasil Builds".

${ }^{6}$ A informação das publicações da obra de Anahory foi recolhida na tese referida de José

Borges sobre o autor, (p. 217, 218); e no arquivo de Rui Ramos.

7 Arquivo de António Neves.

${ }^{8}$ Figura LXVIII.3.

${ }^{9}$ Figura LXVIII.2.

${ }^{10}$ Depoimento telefónico de Luiz Cunha a 14/11/2011.

${ }^{11}$ Idem.

${ }^{12} \mathrm{Idem}$.

${ }^{13}$ Idem. Auzelle, R., (1962) Plaidoyer pour une organisation consciente de l'espace - le roman prosaïque de Monsieur Urbain ed.Vincent, Freal, \& Cie.

${ }^{14}$ Luiz Cunha em 1957-66 e Robert Auzelle 1956-65.

${ }^{15}$ Depoimento telefónico de Luiz Cunha a 14/11/2011.

${ }^{16} \mathrm{Idem}$.

${ }^{17}$ Igreja dos Padres Dominicanos em Fátima e Igreja de São Mamede de Negrelos em Santo Tirso. Idem.

18 1958-70.

19 1963-81.

${ }^{20}$ Depoimento de Nuno Portas a 13/12/2011. A origem da expressão é consensualmente atribuída ao cineasta Francês François Truffaut.

${ }^{21}$ Idem.

${ }^{22} \mathrm{Idem}$

${ }^{23}$ Idem.

${ }^{24}$ Idem.

${ }^{25}$ Depoimento de Duarte Cabral de Mello a 14 /12/2011.

${ }^{26}$ Depoimento de Nuno Portas a 13/12/2011.

${ }^{27}$ Idem.

${ }^{28}$ Depoimento de Duarte Cabral de Mello a 14/12/2011

${ }^{29}$ Depoimento de Nuno Portas a 13/12/2011.

${ }^{30}$ Depoimento de Duarte Cabral de Mello a 14/12/2011.

${ }^{31}$ Idem.

${ }^{32}$ Idem.

${ }_{33}$ Depoimento de Nuno Portas 13/12/2011. 
${ }^{34}$ Esta iniciativa era algo que se intuía no espírito do momento, sendo conhecidas acções similares de apoio à auto-construção na América Latina, tal como foi referido pelo arquitecto Luís Vassalo Rosa, numa Assembleia Geral no Técnico em Maio de 1974, como testemunhou José Charters Monteiro. Depoimento de Charters a 14/12/2011.

${ }_{35}$ Depoimento de Nuno Portas a 13/12/2011.

${ }^{36}$ Depoimento de Keil do Amaral a 13/1/2012.

${ }^{37}$ Idem.

${ }^{38}$ Idem.

39 A edição é totalmente dedicada à Arquitectura em Portugal, Catalunha e País Basco.

40 Os outros autores portugueses são José Augusto França, Manuel Vicente, Carlos Duarte, Gomes da Silva, Manuel Vicente, M:C:G., Duarte Cabral de Mello e Nuno Portas.

${ }^{41}$ Este texto de Gregotti foi editado pela primeira vez, na referida revista Controspazio em 1972.

${ }^{42}$ Foi editado em 1977 um catálogo intitulado Proyecto y ciudad historica. Estiveram presentes Tarrago, Daniele Vitale, Bonet Correa, Ruesga e Villanueva, V. Savi, Unzurrunzaga, Josef Kleihues, Carlo Aymonino, Oswald Mathias Ungers, Carlos Martí Arís, Bruno Reichlin e Fabio Reinhart, entre outros.

43 Depoimento pessoal de José Charters Monteiro a 14/12/2011.

${ }^{44}$ Idem.

${ }^{45} \mathrm{Idem}$.

${ }^{46}$ Também participaram Hollein, Kroll, Martorell, Mackay, Taller de Arquitectura Ambasz, Craig Stanley, Rauch, e como referido, Siza. Meier, Moore e Pelli, embora tivessem trabalhos na exposição não participaram no debate. 